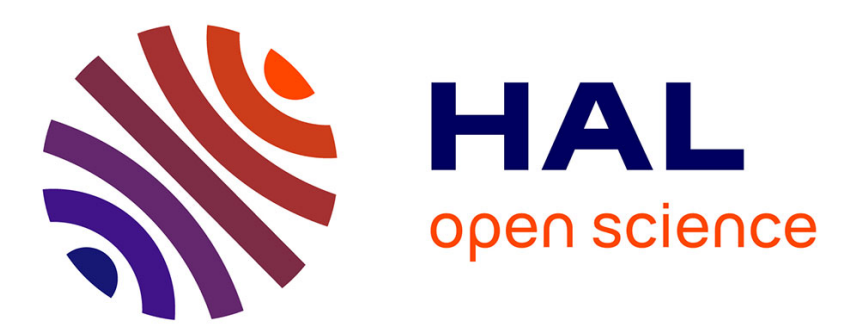

\title{
Negative Outgroup Leader Actions Increase Liking for Ingroup Leaders: An Experimental Test of Intergroup Leader-Enhancement Effects
}

Todd L. Pittinsky, Brian Welle

\section{- To cite this version:}

Todd L. Pittinsky, Brian Welle. Negative Outgroup Leader Actions Increase Liking for Ingroup Leaders: An Experimental Test of Intergroup Leader-Enhancement Effects. Group Processes and Intergroup Relations, 2008, 11 (4), pp.513-523. 10.1177/1368430208095403 . hal-00571702

\section{HAL Id: hal-00571702 \\ https://hal.science/hal-00571702}

Submitted on 1 Mar 2011

HAL is a multi-disciplinary open access archive for the deposit and dissemination of scientific research documents, whether they are published or not. The documents may come from teaching and research institutions in France or abroad, or from public or private research centers.
L'archive ouverte pluridisciplinaire HAL, est destinée au dépôt et à la diffusion de documents scientifiques de niveau recherche, publiés ou non, émanant des établissements d'enseignement et de recherche français ou étrangers, des laboratoires publics ou privés. 


\title{
Negative Outgroup Leader Actions Increase Liking for Ingroup Leaders: An Experimental Test of Intergroup Leader-Enhancement Effects
}

\author{
Todd L. Pittinsky and Brian Welle \\ Harvard Kennedy School
}

\begin{abstract}
We conducted two studies to examine how information about outgroup leaders' negative actions affect ingroup leader favorability ratings. Study 1 found that people hold more favorable attitudes toward ingroup leaders (i.e. their own nation's leaders) when learning of negative actions of outgroup leaders (i.e. another nation's leaders). Study 2 replicated the finding, examining social identity strength as a moderator of this effect, and found that participants with strong national identification exhibit this intergroup leader-enhancement effect but participants with weak national identification do not. These data extend previous research on liking for leaders and are consistent with predictions derived from social identity theory. The implications of these findings for intergroup relations research and the psychological study of leadership are discussed.
\end{abstract}

KEYWORDS leader-enhancement effects, liking

PrIOR to the Watergate scandal, President Richard Nixon consistently held high approval ratings among citizens of the USA. As the scandal became public in the first half of 1973, his approval ratings fell dramatically. Voters disapproved of their leader's actions and withdrew their support for him. While it is common to consider how followers respond to their own leader's actions, one also might wonder about how citizens of other nations responded to news of Nixon's corrupt behavior. Might Nixon's actions have influenced not only their views of him, but also their views of their own leaders? The purpose of the present research is to explore whether the actions of an outgroup leader influence how the members of a group feel about their own leader.

Will the actions of an outgroup leader change how the members of a group feel about their own leader? Many historical accounts suggest that information about outgroup leaders can bolster an ingroup leader's favorability ratings. Such information could even be strategically

\section{Author's note}

Address correspondence to Todd L. Pittinsky, Harvard Kennedy School,

Harvard University, 79 J.F.K. Street, Cambridge, MA 02138, USA

[email: todd@pittinsky.com] 
manipulated for this purpose. If outgroup leader actions do influence the favorability ratings of ingroup leaders, the effect will become more common as global media provide access to ever more information on leaders around the world. And yet this effect has not, to our knowledge, been experimentally tested.

Recent research integrating social identity theory and the study of leadership (Haslam \& Platow, 2001; Hogg, 2001; Lord \& Hall, 2005; van Knippenberg \& van Knippenberg, 2003), creating a social identity theory of leadership (Hogg, 2001; Hogg \& van Knippenberg, 2003; van Knippenberg \& Hogg, 2003), provides a theoretical framework for hypothesizing such effects. The social identity theory of leadership, based on social identity and self-categorization theories, explains leader emergence and effectiveness through consideration of leader prototypicality (De Cremer \& Van Vugt, 2001; Haslam \& Platow, 2001; Hogg \& van Knippenberg, 2003), group members' perceptions of a group leader's fairness (Platow, Hoar, Reid, Harley, \& Morrison, 1997; Platow \& van Knippenberg, 2001), and group members' evaluations of and responses to ingroup leader behavior (Duck \& Fielding, 2003; Hains, Hogg, \& Duck, 1997; Hogg, Hains, \& Mason, 1998).

What about outgroup leaders? Though social identity theory is a theory of intergroup relations, most of the work on the social identity theory of leadership-and related research testing the theory-has considered intragroup implications. The intergroup context, an important direction for research and theory on leadership (Pittinsky, 2007; Pittinsky \& Simon, 2007), provides a potential context-specific influence on followers' judgment of individual leaders (Haslam, Oakes, McGarty, Turner, \& Onorato, 1995; Oakes, Haslam, \& Turner, 1998; Turner \& Haslam, 2001). The examination of leadership in its intergroup context can illuminate leadership in groups and organizations, and within and among nations (Pittinsky, 2007; Pittinsky \& Simon, 2007). In particular, it can illuminate public leadership in government, public sector organizations, and organizations-whether notfor-profit or for-profit- that seek to advance the public good (Pittinsky \& Zhu, 2005), because intergroup leadership raises critical questions about the effects of leadership on those outside a leader's formal group and formal responsibility (Pittinsky \& Simon, 2007). Such questions cut to the core of the common or public good and are often overlooked in the contemporary psychosocial study of leadership conducted in for-profit small-group or organizational settings. ${ }^{1}$

To investigate intergroup leadership effects, we designed a series of studies to examine how knowledge of an outgroup leader's negative actions influence the favorability ratings of ingroup leaders. Based on social identity theory and the corresponding evidence for group enhancement in the intergroup context, we hypothesize an intergroup leader-enhancement effect: information about the negative actions of an outgroup leader will lead group members to feel more favorable toward their own leaders, even in the absence of any new information about their own leaders. As social identity enhancement motives are the key mechanisms hypothesized, we expect this pattern to be observed most clearly among individuals who strongly identify with their group.

\section{Social identity theories of group enhancement motives and intergroup social comparisons}

Social identity theory (Abrams \& Hogg, 1999; Tajfel, 1982; Tajfel \& Turner, 1986; Turner, 1975 ) argues that one way people satisfy their drive for self-esteem is through identification with positively regarded groups. Consequently, just as individuals gauge their own well-being by making comparisons with other individuals (Hakmiller, 1966; Tajfel, 1982; Wills, 1981), group members will sometimes compare their group favorably to other groups (Taylor, Moghaddam, \& Bellerose, 1989). Because comparing one's group positively to another can heighten one's self-esteem, a number of behavioral and perceptual processes can ensure that these comparisons are indeed favorable (Brewer \& Brown, 1998). Moreover, individuals who identify more strongly with the ingroup are more likely to make ingroup-favoring social comparisons (Crocker \& Luhtanen, 1990).

Because leaders represent the traits, attributes, and qualities of their groups to the outside world, they may be an object of social comparison. 
According to the social identity theory of leadership, a leader is often perceived as the most representative or prototypical member of the group, particularly in cases of high group salience or in cases where members and leaders identify strongly with the group (Hains et al., 1997; Haslam \& Platow, 2001; Hogg et al., 1998). Thus, it is reasonable to expect that leader-toleader comparisons would be one of the social comparisons people might make and that an intergroup leader-enhancement effect might appear as one type of ingroup-favoring social comparison. Learning about the negative actions of outgroup leaders (e.g. the leaders of other countries) may actually have a positive impact on people's views of their own leaders. The current studies experimentally test this possibility.

\section{Study 1}

Our first study was designed to examine ingroup members' favorability ratings of ingroup leaders in response to new information about the negative actions of outgroup leaders. We described to participants a pervasive international situation: hunger and malnutrition in another country. In the experimental condition, the hunger and malnutrition were attributed to the negative acts of that country's (outgroup) leaders. In the control condition, the hunger and malnutrition were attributed to a natural event -a drought. Our outcome measure was individuals' favorability ratings of their own (ingroup) leaders.

We used favorability ratings as the dependent measure to operationalize and test predictions about leadership derived from social identity theory. Leader favorability is discussed in many social identity accounts of leadership. For example, the finding that 'systematically selected leaders may be less favorably perceived than randomly appointed leaders' supports the core tenet of leader prototypicality (Haslam et al., 1998, cited in Hogg, 2001, p. 192). Two of the basic building blocks of the social identity theory of leadership are (i) followers' perception of leader effectiveness and (ii) followers' endorsement of their leaders (Hogg, 2001). Past research has demonstrated that favorability ratings tap followers' perception of leadership effectiveness and followers' endorsement of their leaders (Nye \& Forsyth, 1991). In addition, favorability measures have the virtue of being a highly ecologically valid measure, commonly used in polls to compare leaders, make predictions about the likely outcomes of elections, and assess the impact of world events on the public perception of leaders (Newport, 2003).

Based on the social identity and intergroup social comparisons research reviewed earlier, we predicted that when the negative acts of the leaders of an outgroup were described, a groupserving social comparison would be made and the favorability of attitudes toward ingroup leaders would increase. These predictions led to the hypothesis that participants will express greater favorability for ingroup leadership when they believe that another nation's leaders are largely responsible for a negative event.

\section{Method}

Participants The participants were 39 graduate $(N=23)$ and undergraduate $(N=16)$ students at Harvard University, recruited in the entryway of a campus library or through their classes. There were 22 men and 17 women, with an average age of 23.6.

Procedure Participants were asked to take 15 minutes to read about a hypothetical international event and fill out a brief survey. The experimental materials included a one-page description of Lesotho, an African country chosen because pretest data revealed that participants would have little knowledge of current events there.

The description of Lesotho was a composite of data available from the World Food Program. Lesotho was briefly described as one of the world's 49 least-developed countries, which meant it had a per capita GDP under U.S. $\$ 900$, a low level of human-capital development, and high economic vulnerability. Additional information included the population of the country $(2,207,954)$, land area $\left(30,255 \mathrm{~km}^{2}\right)$, population density (72 people $\left./ \mathrm{km}^{2}\right)$, and average life expectancy (49 years). 
After reading the general information about Lesotho, participants were randomly assigned to one of two experimental manipulations and completed a brief questionnaire containing the dependent measures. To further reduce any effects of any particular current event, questions were written in the future tense.

\section{Independent variable}

Responsibility for the situation All participants were given general information about Lesotho; participants read one of two paragraphs describing Lesotho's difficulties. Participants in the outgroup leaders' negative-actions-responsible condition read:

Lesotho is a country that has suffered largely due to the actions of its own leaders. Although the international community has responded with food and monetary supplies for Lesotho, the leaders of Lesotho have diverted the aid inappropriately and irresponsibly. As a result, the population has not been receiving the aid that was allocated to them. Largely as a result of the irresponsible diversion of aid by the leadership of Lesotho, the people of Lesotho will continue to live each day hungry and weakened by the lack of nutrition.

Participants in the nature-responsible (control) condition read:

Lesotho is a country that has suffered largely due to chronic drought. Recently, Lesotho experienced its longest dry spell in 20 years and its second worst drought in a century. The drought has devastated the food production in Lesotho. Many cannot remember the last time it rained. Largely as a result of the drought, the people of Lesotho will continue to live each day hungry and weakened by the lack of nutrition.

Dependent measures There were two dependent measures: 'How favorable would you feel toward the leadership of your country?' and 'How favorable would you feel toward the people of your country?' (1, strongly unfavorable; 7 , strongly favorable). The measures of favorability mirrored techniques currently used in the USA to assess attitudes toward presidents. ${ }^{2}$

Manipulation check We asked participants, 'To what extent would you believe the leadership of Lesotho is responsible for the conditions in
Lesotho?' and 'To what extent would you believe that nature is responsible for the conditions in Lesotho?' (1, not at all; 7 , very much).

\section{Results}

As expected, the mean score for 'Lesotho leadership responsible' was significantly higher in the outgroup leaders' negative-actions-responsible condition $(M=6.79, S D=.42)$ than in the control condition $(M=5.40, S D=1.38 ; t(37)=3.98$, $p<.001)$. Also confirming the effectiveness of the manipulation, the mean score for 'nature responsible' was higher in the nature-responsible condition $(M=6.15, S D=.67)$ than in the outgroup leaders' negative-actions-responsible condition $(M=5.00, S D=1.05 ; t(37)=4.03$, $p<.001) .{ }^{3}$ The two dependent variablesratings of the leadership and the people of the USA-were significantly correlated $(r=.49$, $p=.001)$.

Independent sample $t$-tests were conducted to test our hypotheses. As expected, ratings of ingroup leaders were higher when Lesotho's leaders were deemed responsible for the suffering $(M=3.89, S D=.74)$ than when drought was deemed responsible $(M=2.90, S D=1.12$; $t(37)=3.26, p=.004)$. That is, participants felt more favorably toward their own leaders (i.e. US leaders) when learning about the outgroup leaders' negative actions. Results revealed that participants' ratings of the people of the USA in the leader-responsible condition $(M=4.21$, $S D=.71)$ did not significantly differ from those in the drought-responsible condition $(M=3.85$, $S D=1.09 ; t(37)=1.22, n s)$, demonstrating that this is a leader-enhancement effect and not a general ingroup enhancement effect.

To further demonstrate that the effects of outgroup leaders' actions are independent of participants' pre-existing beliefs about the people of the USA, we conducted an analysis of covariance (ANCOVA) with the independent variable being the source of the negative event, the dependent variable being the evaluation of U.S. leadership, and the covariate being the favorability ratings of the people of the USA. As expected, a significant main effect of responsibility on leadership ratings was revealed $(F(1,37)=7.73, p=.008)$, even when the ratings of the people of the USA were accounted for 
(the covariate was significant; $F(1,37)=9.94$, $p=.003)$.

\section{Study 2}

The results from Study 1 provided initial evidence that outgroup leaders' actions can influence the way people think about their own national leaders. Our second study was designed to examine how people's social identification with their nation may moderate the effect found in Study 1. We described the same international situation to participants (hunger and malnutrition in another nation) but we also measured participants' identification with their nation.

Based on the research reviewed earlier, which demonstrated that identification moderates ingroup favoring intergroup comparisons, we examined whether individuals' national identification would moderate how they used information about outgroup leaders to shape their favorability ratings of ingroup leaders. We tested prediction that the more strongly people identify with their national group, the more likely they will be to view their leader more favorably in contrast to a poorly performing outgroup leader. We expected to find that individuals with stronger social identification would, overall, have more favorable attitudes toward their ingroup leaders (Platow \& van Knippenberg, 2001). We further expected that individuals with stronger social identification would be more likely to be influenced by information about outgroup leaders and would therefore make leader-enhancing social comparisons.

\section{Method}

Participants Seventy-nine Harvard University undergraduate students, 46 women and 33 men, were randomly assigned to one of two experimental conditions. All but four of the participants were U.S. citizens. The average age was 20.5 years.

Procedure Upon entering the experiment website, participants were shown a description of Lesotho. The materials were the same as those used in Study 1, but with one difference: the vignette was written in the present tense to make it more powerful-not a hypothetical situation but something that was really happening. After reading the general information about Lesotho, participants were exposed to the experimental manipulation and completed a brief questionnaire containing the dependent measures.

\section{Independent variable}

Responsibility for situation Having read the general information about Lesotho, participants read a paragraph-either the outgroup leaders' negative-actions-responsible scenario or the nature-responsible scenario-explaining why that nation is experiencing difficulties.

National identification To assess strength of identification, we used one of the four subscales of Luhtanen and Crocker's (1992) Collective Self-Esteem Scale, the four-item 'importance to identity' subscale, which has been shown to reflect the centrality of an identity to one's sense of self (Luhtanen \& Crocker, 1992). We used all four items of the subscale, modifying the language as necessary to refer to participants' national identities. Responses were made on a 7-point scale (1, agree; 7, disagree), with higher scores indicating stronger national identification. The 4-item scale was reliable $(\alpha=.83)$.

This particular subscale has been used by many researchers as a measure of group identification (Carvallo \& Pelham, 2006; Chen, Chen, \& Shaw, 2004; Eccleston \& Major, 2006; Sellers, Rowley, Chavous, Shelton, \& Smith, 1997; Vorauer \& Turpie, 2004). The subscale conceptualizes identity as the importance of the group to self-concept and self-definition and is often recognized as conceptually tapping identification rather than self-esteem (Ahlering, 2003; Branscombe, Schmitt, \& Harvey, 1999; Cassidy, O'Connor, Howe, \& Warden, 2004), serving as an explicit measure of the importance of collective identity (Ashmore, Deaux, \& McLaughlin-Volpe, 2004).

Dependent measures The same two dependent measures of favorability were collected in this study as in the previous study. 


\section{Results}

Our predictions were tested using linear regression, with the predictor variables being the experimental conditions (outgroup leaders' negative-actions-responsible or natureresponsible) and the 'importance to identity' subscale of collective self-esteem. In the first step, we entered the main effects into the equation; in the second step we entered their interactions.

Liking for ingroup leader We first looked for any differences in national identity strength between participants in the outgroup leaders' negative-action-responsible and natureresponsible conditions. There was no significant difference; $t(78)=-.91, p=.99$.

To investigate whether national identity strength would moderate the relationship between perceived responsibility for suffering and favorability ratings of ingroup leaders, we conducted a hierarchical regression analysis. The results confirmed our hypothesis that the more strongly people identify with their nation, the more likely it is that outgroup leaders' actions will affect their perceptions of their own leader (see Table 1). Neither a main effect for responsibility $(\beta=.18)$ nor national identity $(\beta=.05)$ was significant after the interaction was entered into the model. However, the interaction between responsibility and national identity was significant $\left(\beta=.28, \Delta R^{2}=.05, p=.04\right)$. This confirmed our hypothesis: the more strongly people identify with their nation, the more likely it is that outgroup leaders' actions will affect their perceptions of their own leaders.
To further confirm this conclusion, we followed the recommendations of Aiken and West (1991) by plotting favorability scores for those in the 'drought' and 'their leader' conditions at one standard deviation above and below the mean for social identity. Results of this analysis (see Figure 1) showed that learning that outgroup leaders acted negatively increased the favorability ratings of ingroup leaders for those with higher national identification but not for those with lower national identification. Social identity was positively related to favorability ratings in the outgroup leaders' negative-actionresponsible condition (simple slopes analysis for one standard deviation above the mean of social identity: $\beta=.37, p=.01$ ) but not in the nature-responsible control condition (simple slope analysis for one standard deviation below the mean of standard deviation: $\beta=-.01, n s)$. In other words, learning that outgroup leaders acted negatively increased the favorability ratings of ingroup leaders but only for those with higher not lower national identification.

Liking for ingroup members None of the independent variables and none of their interactions affected attitudes toward one's own people (responsibility, $\beta=.12$; national identity, $\beta=.03$; responsibility $\times$ identity, $\beta=.21$ ).

\section{General discussion}

The degree to which members of a group feel favorably towards their leaders is a critical issue. In the USA, for example, an array of

Table 1. Hierarchical regression results for Study 2: The effect of responsibility and national identity on favorability ratings of ingroup leaders and ingroup members

\begin{tabular}{|c|c|c|c|c|}
\hline & \multicolumn{2}{|c|}{$\underline{\text { Favorability of leaders }}$} & \multicolumn{2}{|c|}{ Favorability of people } \\
\hline & Step 1 & Step 2 & Step 1 & Step 2 \\
\hline Responsibility (Beta) & .19 & .18 & .13 & .12 \\
\hline National identity (Beta) & .21 & .05 & .16 & .03 \\
\hline Responsibility $\times$ identity (Beta) & & $.28 *$ & & .21 \\
\hline$R^{2}$ & .09 & .14 & .05 & .07 \\
\hline$F$ & $3.73^{*}$ & $4.00 *$ & 1.82 & 2.01 \\
\hline$\Delta R^{2}$ for step 2 & & .05 & & .03 \\
\hline$F$ for $\Delta R^{2}$ & & $4.22 *$ & & 2.33 \\
\hline
\end{tabular}

$* p<.05$. 


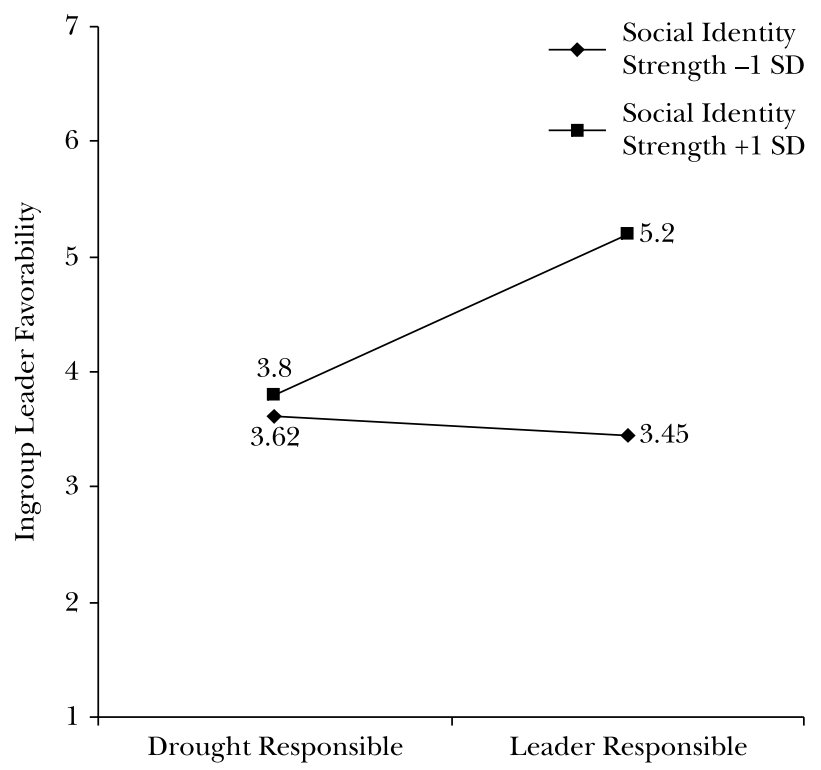

Figure 1. Relationship between identity strength and leader favorability evaluation as a function of nature/ leader responsibility (for Study 2).

research programs map fluctuations in the public's attitudes toward the national leadership (Newport, 2003; Pittinsky, Rosenthal, Bacon, Montoya, \& Zhu, 2006). The results from the present study demonstrated an intergroup leader-enhancement effect: liking for one's leader increased in the context of ingrouppositive leader comparisons. This effect, the research found, is particular and leader-specific and not a more general social comparison effect. Further, we found that the more strongly people identify with their group (which, in this research, is their nation), the more likely they are to view their leader more favorably in response to negative information about an outgroup leader.

In the context studied (i.e. public leadership and cross-national comparisons), the data suggest that increased liking for a domestic leader may result from citizens learning about the negative actions of foreign leaders. Indeed, our findings suggest that leaders might influence their own favorability ratings by selectively communicating information about the negative actions of outgroup leaders or by focusing domestic attention on those actions. Apart from leaders' manipulations of information, the media a person chooses to consume would likely influence how favorably that person views their leaders, depending on the breadth and depth of reporting of international leaders' misdeeds.

As a first set of empirical studies, the present investigation has several limitations that are recognized here and should be addressed in future work. First, our studies relied on student samples that may not be representative of the full population. However, our sample mirrors the research samples typically used in social identity research, thereby allowing comparability across studies. Second, we measured rather than manipulated national identity. The study of existing national identity groups (Platow et al., 1997) enhances ecological validity, a richness that necessarily comes at the expense of some measure of experimental control. Relying on measurement rather than manipulation raises issues of ultimate causation. In social identity research, however, laboratory studies and field research have often produced similar results (Platow \& van Knippenberg, 2001). 
Despite these limitations, the present research provides evidence that outgroup leader behavior is important to understanding favorability ratings of an ingroup leader and that social identification is an important moderator of the effects of outgroup leaders on ingroup leader favorability ratings. These studies provide empirical support for the development of theories that examine intergroup leadership processesdynamics that occur across groups and, more specifically, across group leaders.

We conclude with an examination of some of the most compelling directions for future research. The current studies examine negative leader acts. A logical future step is to examine cases in which outgroup leaders take positive actions. Predictions that can be made directly from social identity theory (e.g. that people with a high level of national identification would not like their leaders less when confronted with the positive acts of outgroup leaders, while people with a low level of national identification would rate their leaders less favorably when so confronted) await empirical confirmation. Another important direction for future research relates to the measurement of political affiliation as a moderator in multiparty political systems. Some of the variance in our Study 2 data may have been influenced by political affiliation. Future research that explicitly looks at the potential moderating effects of political affiliation will likely provide a more nuanced view of the interaction between political affiliation and identification with the national collective. Finally, an interesting topic for future research is the extent to which people ascribe intentional control over the dissemination of information about outgroup leaders' actions. Would the salience of the strategic motives for the communication of such information by one's own ingroup leaders alter, eliminate, or even reverse the enhancement effect?

The present research sought to gain a better understanding of why a leader may be viewed favorably or unfavorably. The intergroup leaderenhancement effect revealed in this research, relevant to the many different contexts in which psychologists examine intergroup relations, suggests that researchers may need to look beyond a leader and beyond their followers to other groups and to their leaders.

\section{Notes}

1. For example, a literature examines U.S. presidential leadership (Winter, 1987; for a review, see Goethals, 2005) and political support for leaders from psychological perspectives (Cohen, Solomon, Maxfield, Pyszczynski, \& Greenberg, 2004; Hoyt, Simon, \& Reid, in press; Landau et al., 2004).

2. For example, one of the measures the Gallup Poll uses most frequently asks Americans to 'Please tell me if you have a favorable or unfavorable opinion of the current president.'

3. We collected data on a third condition in which ingroup leadership (i.e. U.S.) acted negatively (i.e. diverted aid). This condition was run to ensure that negative actions by an ingroup leader did not give rise to the same ratings as negative actions by an outgroup leader. In other words, it was an alternative control condition. Univariate analysis of variance (ANOVA) showed that this condition had the same (lack of) impact on ratings of U.S. leadership as did the nature-responsible (drought) condition $(M=2.86, F(2,58)=4.33, p<.05)$, with ratings being higher in the outgroup leaders' negative-action-responsible condition than in the ingroup leaders' negative-action-responsible condition and no difference between the nature-responsible and the ingroup leaders' negative-action-responsible conditions.

\section{Acknowledgments}

The authors thank R. Matthew Montoya, Laura Bacon, Laura Maruskin, Seth Rosenthal, Sloan Strike, Stefanie Simon, and John Elder for helpful comments on an early draft of this manuscript. Four anonymous reviewers and the editor of this Journal provided helpful comments on an earlier version of this manuscript. Data from this manuscript were first presented at the American Psychological Society's Annual Conference (2004). The Center for Public Leadership, the Ash Institute for Democratic Governance and Innovation, and the Dean's Research Fund at the Harvard Kennedy School, Harvard University, provided financial support for this research. 


\section{References}

Abrams, D., \& Hogg, M. A. (Eds.). (1999). Social identity and social cognition. Oxford, UK: Blackwell.

Ahlering, R. (2003). Collective self-esteem data from four ethnic groups. Psychological Reports, 92, 562-564.

Aiken, L. S., \& West, S. G. (1991). Multiple regression: Testing and interpreting interactions. Newbury Park, CA: SAGE.

Ashmore, R. D., Deaux, K., \& McLaughlin-Volpe, T. (2004). An organizing framework for collective identity: Articulation and significance of multidimensionality. Psychological Bulletin, 130, 80-114.

Branscombe, N. R., Schmitt, M. T., \& Harvey, R. D. (1999). Perceiving pervasive discrimination among African Americans: Implications for group identification and well-being. Journal of Personality and Social Psychology, 77, 135-149.

Brewer, M. B., \& Brown, R. J. (1998). Intergroup relations. In D. T. Gilbert, S. T. Fiske, \& G. Linzey (Eds.), The handbook of social psychology (Vol. 2, 4th ed., pp. 99-142). Oxford, UK: Oxford University Press.

Carvallo, M., \& Pelham, B. W. (2006). When fiends become friends: The need to belong and perceptions of personal and group discrimination. Journal of Personality and Social Psychology, 90(1), 94-108.

Cassidy, C., O’Connor, R. C., Howe, C., \& Warden, D. (2004). Perceived discrimination and psychological distress: The role of personal and ethnic self-esteem. Journal of Counseling Psychology, 51(3), 329-339.

Chen, S., Chen, K. Y., \& Shaw, L. (2004). Self-verification motives at the collective level of self-definition. Journal of Personality and Social Psychology, 86, 77-94.

Cohen, F., Solomon, S., Maxfield, M., Pyszczynski, T., \& Greenberg, J. (2004). Fatal Attraction: The effects of mortality salience on evaluations of charismatic, task-orientated, and relationshiporientated leaders. Psychological Science, 15, 846-851.

Crocker, J., \& Luhtanen, R. (1990). Collective self-esteem and ingroup bias. Journal of Personality and Social Psychology, 58, 60-77.

De Cremer, D., \& Van Vugt, M. (2001). Intergroup and intragroup aspects of leadership in social dilemmas: A relational model of cooperation.
Journal of Experimental Social Psychology, 38, 126-136.

Duck, J. M., \& Fielding, K. S. (2003). Leaders and their treatment of subgroups: Implications for evaluations of the leader and the superordinate group. European Journal of Social Psychology, 33, 387-401.

Eccleston, C. P., \& Major, B. N. (2006). Attribution to discrimination and self-esteem: The role of group identification and appraisals. Group Processes $\mathcal{E}$ Intergroup Relations, 9(2), 147-162.

Goethals, G. R. (2005). Presidential leadership. Annual Review of Psychology, 56, 545-570.

Hains, S. C., Hogg, M. A., \& Duck, J. M. (1997). Self-categorization and leadership: Effects of group prototypicality and leader stereotypicality. Personality and Social Psychology Bulletin, 23, 1087-1099.

Hakmiller, K. L. (1966). Need for self-evaluation, perceived similarity and comparison choice. Journal of Experimental Social Psychology Supplement, $1,49-54$.

Haslam, S. A., McGarty, C., Brown, P. M., Eggins, R. A., Morrison, B. E., \& Reynolds, K. J. (1998). Inspecting the emperor's clothes: Evidence that random selection of leaders can enhance group performance. Group Dynamics: Theory, Research, and Practice, 2, 168-184.

Haslam, S. A., Oakes, P. J., McGarty, C., Turner, J. C., \& Onorato, R. S. (1995). Contextual changes in the prototypicality of extreme and moderate outgroup members. European Journal of Social Psychology, 25, 509-530.

Haslam, S. A., \& Platow, M. J. (2001). The link between leadership and followership: How affirming social identity translates vision into action. Personality and Social Psychology Bulletin, 27, 1469-1479.

Hogg, M. A. (2001). A social identity theory of leadership. Personality and Social Psychology Review, 5, 184-200.

Hogg, M. A., Hains, S. C., \& Mason, I. (1998). Identification and leadership in small groups: Salience, frame of reference, and leader stereotypicality effects on leader evaluations. Journal of Personality and Social Psychology, 75, 1248-1263.

Hogg, M. A. \& Van Knippenberg, D. (2003). Social identity and leadership processes in groups. In M. P. Zanna (Ed.), Advances in experimental social psychology (Vol. 35, pp. 1-52). San Diego, CA: Academic Press. 
Hoyt, C., Simon, S., \& Reid, L. (in press). The effect of mortality salience on leader preference based on gender. The Leadership Quarterly.

Landau, M. J., Solomon, S., Greenberg, J., Cohen, F., Pyszczynski, T., \& Arndt, J. (2004). Deliver us from evil: The effects of mortality salience and reminders of 9/11 on support for President George G. Bush. Personality and Social Psychology Bulletin, 30, 1136-1150.

Lord, R. G., \& Hall, R. J. (2005). Identity, deep structure and the development of leadership skills. Leadership Quarterly, 16, 591-615.

Luhtanen, R., \& Crocker, J. (1992). A collective self-esteem scale: Self-evaluation of one's social identity. Personality and Social Psychology Bulletin, 18, 302-318.

Newport, F. (2003, October 28). Bush's favorable rating running higher than job approval. Gallup Poll Tuesday Briefing.

Nye, J. L., \& Forsyth, D. R. (1991). The effects of prototype-based biases on leadership appraisals. Small Group Research, 22(3), 360-379.

Oakes, P., Haslam, S. A., \& Turner, J. C. (1998). The role of prototypicality in group influence and cohesion: Contextual variation in the graded structure of social categories. In S. Worchel, J. F. Morales, D. Páez, \& J. Deschamps (Eds.), Social identity: International perspectives (pp. 75-92). Thousand Oaks, CA: SAGE.

Pittinsky, T. L. (2007). The science and practice of intergroup leadership. In T. L. Pittinsky (Ed.), Crossing the divide: Intergroup leadership in a world of difference. Manuscript in preparation.

Pittinsky, T. L., Rosenthal, S. A., Bacon, L. M., Montoya, R. M., \& Zhu, W. (2006). National Leadership Index 2006: A national study of confidence in leadership. Cambridge, MA: Center for Public Leadership, Harvard Kennedy School.

Pittinsky, T. L., \& Simon, S. (2007). Intergroup leadership. The Leadership Quarterly, 18(6), 586-605.

Pittinsky, T. L., \& Zhu, C. (2005). Contemporary public leadership in China: A research review and consideration. Leadership Quarterly, 16, 921-939.

Platow, M. J., Hoar, S., Reid, S., Harley, K., \& Morrison, D. (1997). Endorsement of distributively fair and unfair leaders in interpersonal and intergroup situations. European Journal of Social Psychology, 27, 465-494.

Platow, M. J., \& Van Knippenberg, D. (2001).
A social identity analysis of leadership endorsement: The effects of leader ingroup prototypicality and distributive intergroup fairness. Personality and Social Psychology Bulletin, 27, 1508-1519.

Sellers, R. M., Rowley, S., Chavous, T. M., Shelton, J. N., \& Smith, M. A. (1997). The multidimensional inventory of Black identity: Construct validity and reliability. Journal of Personality and Social Psychology, 73, 805-815.

Tajfel, H. (1982). Social psychology of intergroup relations. Annual Review of Psychology, 33, 1-39.

Tajfel, H., \& Turner, J. C. (1986). The social identity theory of inter-group behavior. In S. Worchel \& L. W. Austin (Eds.), Psychology of intergroup relations (pp. 33-48). Chicago: Nelson-Hall.

Taylor, D. M., Moghaddam, F. M., \& Bellerose, J. (1989). Social comparison in an intergroup context. Journal of Social Psychology, 129, 499-515.

Turner, J. C. (1975). Social comparison and social identity: Some prospects for intergroup behaviour. European Journal of Social Psychology, 5, 5-34.

Turner, J. C., \& Haslam, S. A. (2001). Social identity, organizations and leadership. In M. E. Turner (Ed.), Groups at work. Advances in theory and research (pp. 25-67). Hillsdale, NJ: Erlbaum.

Van Knippenberg, D., \& Hogg, M. A. (2003). A social identity model of leadership effectiveness in organizations. Oxford, UK: Elsevier Science.

Van Knippenberg, B., \& Van Knippenberg, D. (2003). Leadership, identity and influence: Relational concerns in the use of influence tactics. In D. Van Knippenberg \& M. A. Hogg (Eds.), Leadership and power: Identity processes in groups and organizations. London: SAGE.

Vorauer, J. D., \& Turpie, C. A. (2004). Disruptive effects of vigilance on dominant group members' treatment of outgroup members: Choking versus shining under pressure. Journal of Personality and Social Psychology, 87, 384-399.

Wills, T. A. (1981). Downward social comparison principles in social psychology. Psychological Bulletin, 90, 245-271.

Winter, D. G., (1987). Leader appeal, leader performance, and the motive profiles of leaders and followers: A study of American presidents and elections. Journal of Personality and Social Psychology, 52, 196-202.

Paper received 22 July 2006; revised version accepted 4 March 2008. 


\section{Biographical notes}

TODD L. PITTINSKY is an associate professor at the Harvard Kennedy School, and research director of the Center for Public Leadership. His research investigates allophilia and the two-dimensional model of intergroup leadership. Todd earned his A.. in psychology from Yale University, and his M.A. in psychology and PhD in organizational behavior from Harvard University.
BRIAN WELLE is a research scientist at Google Inc., where he co-leads the People and Innovation Lab. His current projects focus on organizational culture and employee selection. Prior to Google, Welle studied leadership as a post-doc at the Center for Public Leadership. He received his PhD in Organizational Psychology from NYU. 